\title{
ENTOMOPTER MANEUVERABILITY EXCHANGED BY DEFORMATIONS CONTROL OF FLEXIBLE FLAPPING WINGS
}

\section{PODNIESIENIE MANEWROWOŚCI ENTOMOPTERA POPRZEZ STEROWANIE DEFORMACJAMI ODKSZTALCALNYCH MACHAJĄCYCH SKRZYDEL}

\section{Grzegorz Kowalczyk, Jerzy Lewitowicz, Krzysztof Sibilski}

Air Force Institute of Technology, Warsaw, 01-494, Poland

\begin{abstract}
In the background of preparing this paper lies our believe that transferring ideas from the more matured disciple like aircraft technology to emerging animal technology should be beneficial for the later one and vice-versa. One integrated idea, of special interest to both disciplines, is the active flexible wing concept. In this paper we developed aeroelastic analysis for a flexible wing for an imposed harmonic flapping motion about the root chord of the wing. A Matlab code was written based on the analysis. This code was used to find the average lift and thrust of a wing of known aerodynamic and structural properties.
\end{abstract}

Keywords: Flapping wings Micro Aerial Vehicles (MAV), aeroelastic analysis. Entomopter flight dynamics and control

Streszczenie: Podstawą podjęcia tej pracy było nasze przekonanie o celowości przeniesienia idei bionicznych do zasad budowy miniaturowych statków powietrznych. Jedną z takich idei jest koncepcja aktywnie odkształcalnych skrzydeł. Na wstępie przedstawiliśmy aeroelastyczne analizy odkształcalnych skrzydeł wykonujących wymuszone ruchy harmoniczne względem cięciwy znajdującej się $\mathrm{u}$ ich nasady. Na podstawie tych analiz opracowaliśmy pakiet programów w środowisku Matlab. Następnie pakiet ten zastosowaliśmy do obliczeń średniej wartości siły nośnej i siły ciągu odkształcalnego skrzydła.

Słowa kluczowe: Miniaturowe Bezzałogowe Statki Powietrzne (mBSL) z machającymi skrzydłami, aeroelastyczność, dynamika lotu i sterowanie mBSL-i, dynamika lotu i sterowanie entomoptera, 


\section{Introduction}

Research groups in University of Toronto have successfully built and flown ornithopters. The design and development of an entomopter is a complex multidisciplinary task. Air Force Institute of Technology in Poland, has presently initiated a project to design, build and fly an entomopter. Present work is towards this effort.

Design and development of an efficient wing is a primary requirement towards making an ornithopter. Ornithopter wings have its flapping motion accompanied by a twisting motion. The flapping motion is the rotation of the outboard wing about the hinge line along the root chord. The twisting motion is the rotation of aerofoil sections at each spanwise location about a chordwise location. Early researchers have shown that a definite relation exists between flapping and twisting for optimum aerodynamic performance. An actuation system is required for the flapping motion. The twisting motion can be produced in a number of ways:

- By using distributed actuators on the wing to get the required twist distribution along the span.

- By having one actuator at the tip to rotate the tip of the wing relative to the root. This along with suitable aeroelastic tailoring of the wing can bring about the required twist distribution.

- By using one external flapping actuator and relying on the aerodynamic and inertial loads along with suitable aeroelastic tailoring of the wing to bring about the required twisting motion.

In this work, the flapping and twisting motion using only one external actuator is attempted. This actuator is for producing the flapping motion. To obtain the required twist distribution we need to suitably tailor the flexibility of the wing. This is called the aeroelastic tailoring of the wing.

To accomplish this task, an aeroelastic model of the flapping wing is developed using strip theory $[1,2,4]$. For a structurally and aerodynamically defined wing and a specified kinematics at the actuation point, the aeroelastic model gives the bending and twisting deformations and aerodynamic and inertial loads as a function of time. The aeroelastic model of the wing is validated with results given in the literature.

\section{Structural Modelling of the Entomopter Wing}

The structural analysis was done for a generic ornithopter wing [2]. The wing is divided into a number of strips in the spanwise direction as shown in figure 1 . The bending displacements $h_{i}$ and the twist $\theta_{i}$ of the wing are considered at each of these strips. It is assumed that the structural properties and geometric properties such as $G J_{i}$ and $E I_{i}$ are constant on each of these strips. However, these properties may vary from one strip to the other strip. Using these properties, the flexibility matrix of the wing is calculated $[3,5]$. If the wing is divided into 
$\mathrm{N}$ spanwise segments, the order of the flexibility matrix will be $2 N \times 2 N$ as shown below.

Flexibility matrix $(\mathrm{C})=\left[\begin{array}{ll}{\left[C_{h h}\right]} & {\left[C_{h \theta}\right]} \\ {\left[C_{\theta h}\right]} & {\left[C_{\theta \theta}\right]}\end{array}\right]$

Where $\left[C_{h h}\right],\left[C_{h \theta}\right],\left[C_{\theta h}\right]$ and $\left[C_{\theta \theta}\right]$ are the flexibility matrices, each of order $N \times N$.

\section{Aeroelastic modeling of the flapping wing}

The structural analysis was done for a generic ornithopter wing [2]. The wing is divided into a number of strips in the spanwise direction as shown in figure 1 . The bending displacements $h_{i}$ and the twist $\theta_{i}$ of the wing are considered at each of these strips. It is assumed that the structural properties and geometric properties such as $G J_{i}$ and $E I_{i}$ are constant on each of these strips. However, these properties may vary from one strip to the other strip. Using these properties, the flexibility matrix of the wing is calculated [3,5]. If the wing is divided into $\mathrm{N}$ spanwise segments, the order of the flexibility matrix will be $2 N \times 2 N$ as shown below.

Flexibility matrix $(\mathrm{C})=\left[\begin{array}{ll}{\left[C_{h h}\right]} & {\left[C_{h \theta}\right]} \\ {\left[C_{\theta h}\right]} & {\left[C_{\theta \theta}\right]}\end{array}\right]$

Where $\left[C_{h h}\right],\left[C_{h \theta}\right],\left[C_{\theta h}\right]$ and $\left[C_{\theta \theta}\right]$ are the flexibility matrices, each of order $N \times N$.

\section{Aeroelastic modeling of the flapping wing}

The bending and twisting displacements at $\mathrm{N}$ segments of the wing are given by the column vectors $\{h\}$ and $\{\theta\}$.

The spar is assumed to have an imposed time varying displacement, $\left\{\mathrm{h}_{0}\right\}$, from the external actuation at the root and $\{\overline{\mathrm{h}}\}$ is the elastic displacement, so that

$$
\{h\}=\left\{h_{0}\right\}+\{\bar{h}\}
$$

The over-bar denotes the elastic displacement. Likewise, $\{\theta\}$ consists of the flapping-axis angle $\left\{\theta_{\mathrm{a}}\right\}$, a built in pre-twist distribution. $\left\{\theta_{\mathrm{w}}\right\}$ and an elastic component, $\{\bar{\theta}\}$.

$$
\{\theta\}=\left\{\theta_{\mathrm{a}}\right\}+\left\{\theta_{\mathrm{w}}\right\}+\{\bar{\theta}\}
$$


The loads and pitching moment respectively, acting on different spanwise segments of the wing are represented by column vectors $\{N\}$ and $\{M\}$. Each element of the load vector, $\mathrm{N}_{\mathrm{i}}$ acts perpendicular to the chord and each element of the moment vector, $\mathrm{M}_{\mathrm{i}}$ acts about the elastic axis and has the same sense and orientation as $\theta_{\mathrm{i}}$ as shown in figures 2 and 3 . Therefore, the loads and deformations are related through the structural flexibility influence coefficients as follows.

$$
\begin{gathered}
{\left[\begin{array}{ll}
{\left[C_{h h}\right]} & {\left[C_{h \theta}\right]} \\
{\left[C_{\theta h}\right]} & {\left[C_{\theta \theta}\right]}
\end{array}\right]\left\{\begin{array}{l}
\{N\} \\
\{M\}
\end{array}\right\}=\left\{\begin{array}{l}
\{\bar{h}\} \\
\{\bar{\theta}\}
\end{array}\right\}} \\
N_{i}=\left(N_{\text {aero }}\right)_{i}+\left(N_{\text {inertia }}\right)_{i} \\
M_{i}=\left(M_{\text {aero }}\right)_{i}+\left(M_{\text {inertia }}\right)_{i}
\end{gathered}
$$

The expression for $\left(\mathrm{N}_{\text {aero }}\right)_{i}$ is given in equation (26). The expressions for the inertial terms, $\left(N_{\text {inertia }}\right)_{i}$ and $\left(M_{\text {inertia }}\right)_{i}$, are given in ref [3].

$$
\left(\mathrm{M}_{\mathrm{aero}}\right)_{\mathrm{i}}=\left(\mathrm{M}_{\mathrm{ac}}\right)_{\mathrm{i}}-\left(\mathrm{N}_{\mathrm{c}}\right)_{\mathrm{i}}\left(0.25 \mathrm{c}_{\mathrm{i}}-\mathrm{e}_{\mathrm{i}}\right)-\left(\mathrm{N}_{\mathrm{a}}\right)_{\mathrm{i}}\left(0.5 \mathrm{c}_{\mathrm{i}}-\mathrm{e}_{\mathrm{i}}\right)
$$

where $e_{i}$ is the distance of the elastic axis from the leading edge. $\left(M_{a c}\right)_{i}$ is the moment about the aerodynamic center.

$$
\left(\mathrm{M}_{\mathrm{ac}}\right)_{\mathrm{i}}=\left(\mathrm{C}_{\mathrm{m}_{\mathrm{ac}}}\right)_{\mathrm{i}} \frac{\rho \mathrm{U}^{2}}{2} \mathrm{C}_{\mathrm{i}}^{2} \Delta \mathrm{y}_{\mathrm{i}}
$$

The expressions for $\mathrm{N}_{\mathrm{i}}$ and $\mathrm{M}_{\mathrm{i}}$ can be separated to static and dynamic terms.

$$
\begin{aligned}
& \mathrm{N}_{\mathrm{i}}=\left(\mathrm{N}_{\text {stat }}\right)_{\mathrm{i}}+\left(\mathrm{N}_{\text {dyn }}\right)_{\mathrm{i}} \\
& \mathrm{M}_{\mathrm{i}}=\left(\mathrm{M}_{\text {stat }}\right)_{\mathrm{i}}+\left(\mathrm{M}_{\text {dyn }}\right)_{\mathrm{i}} \\
& \overline{\mathrm{h}}_{\mathrm{i}}=\Delta \overline{\mathrm{h}}_{\mathrm{i}}+\delta \mathrm{h}_{\mathrm{i}} \\
& \bar{\theta}_{\mathrm{i}}=\Delta \bar{\theta}_{\mathrm{i}}+\delta \theta_{\mathrm{i}}
\end{aligned}
$$

where $\left(\mathrm{N}_{\text {stat }}\right)_{\mathrm{i}}$ and $\left(\mathrm{M}_{\text {stat }}\right)_{\mathrm{i}}$ are the aerodynamic and gravity loads on a non-flapping wing; and $\left(N_{d y n}\right)_{i}$ and $\left(M_{d y n}\right)_{i}$, are the aerodynamic and inertial loads generated by wing's motion. The mean values, $\Delta \overline{\mathrm{h}}_{\mathrm{i}}$ and $\Delta \bar{\theta}_{\mathrm{i}}$ are the non-flapping elastic 
Podniesienie manewrowości entomoptera...

deformation, relative to zero wind configuration. $\delta h_{i}$ and $\delta \theta_{i}$ are the time varying elastic deformations relative to the mean value. Substituting equations (8), (9), (10) and (11) in the equation (3) we get,

$$
\left[\begin{array}{ll}
{\left[C_{h h}\right]} & {\left[C_{h \theta}\right]} \\
{\left[C_{\theta h}\right]} & {\left[C_{\theta \theta}\right]}
\end{array}\right]\left\{\left\{\begin{array}{l}
\left\{N_{\text {stat }}\right\} \\
\left\{M_{\text {stat }}\right\}
\end{array}\right\}+\left[\begin{array}{ll}
{\left[C_{h h}\right]} & {\left[C_{h \theta}\right]} \\
{\left[C_{\theta h}\right]} & {\left[C_{\theta \theta}\right]}
\end{array}\right]\left\{\begin{array}{l}
\left\{N_{d y n}\right\} \\
\left\{M_{d y n}\right\}
\end{array}\right\}=\left\{\begin{array}{l}
\{\Delta \bar{h}\} \\
\{\Delta \bar{\theta}\}
\end{array}\right\}+\left\{\begin{array}{l}
\{\delta h\} \\
\{\delta \theta\}
\end{array}\right\}\right.
$$

By separating the static part and dynamic parts of the equation (12), one can write the static part as,

$$
\left[\begin{array}{ll}
{\left[C_{h h}\right]} & {\left[C_{h \theta}\right]} \\
{\left[C_{\theta h}\right]} & {\left[C_{\theta \theta}\right]}
\end{array}\right]\left\{\begin{array}{l}
\left\{N_{\text {stat }}\right\} \\
\left\{M_{\text {stat }}\right\}
\end{array}\right\}=\left\{\begin{array}{l}
\{\Delta \bar{h}\} \\
\{\Delta \bar{\theta}\}
\end{array}\right\}
$$

When the expressions of $\left(\mathrm{N}_{\text {stat }}\right)_{i}$ and $\left(\mathrm{M}_{\text {stat }}\right)_{i}$ given by equations (4), (5), (8) and (9) are substituted in the above equation, it expands to the form below.

$$
\left[\begin{array}{ll}
{\left[C_{h h}\right]} & {\left[C_{h \theta}\right]} \\
{\left[C_{\theta h}\right]} & {\left[C_{\theta \theta}\right]}
\end{array}\right]\left\{\begin{array}{c}
\left\{a_{1}\left(\bar{\theta}_{a}+\bar{\theta}_{w}+\Delta \bar{\theta}+\alpha_{0}\right)-m_{w} g\right\} \\
\left\{b_{1}\left(\bar{\theta}_{a}+\bar{\theta}_{w}+\Delta \bar{\theta}+\alpha_{0}\right)+\left(M_{a c}\right)\right\}
\end{array}\right\}=\left\{\begin{array}{l}
\{\Delta \bar{h}\} \\
\{\Delta \bar{\theta}\}
\end{array}\right\}
$$

where

$$
\begin{aligned}
\left(\mathrm{N}_{\text {stat }}\right)_{\text {aero }} & =\mathrm{a}_{1}\left(\bar{\theta}_{\mathrm{a}}+\bar{\theta}_{\mathrm{w}}+\Delta \bar{\theta}+\alpha_{0}\right) \\
\left(M_{\text {stat }}\right)_{\text {aero }} & =b_{1}\left(\bar{\theta}_{a}+\bar{\theta}_{w}+\Delta \bar{\theta}+\alpha_{0}\right)+\left(M_{a c}\right)
\end{aligned}
$$

The expressions for the aerodynamic coefficients $a_{1}$ and $a_{2}$ are given in the ref [3]. $\mathrm{m}_{\mathrm{w}}$ denotes the mass of the wing and $\alpha_{0}$ is angle of section's zero lift line with the chord. The equation (14) is further simplified to,

$$
\left\{\begin{array}{l}
\{\Delta \bar{h}\} \\
\{\Delta \bar{\theta}\}
\end{array}\right\}=\left[\begin{array}{cc}
-[I] & {\left[A_{1}\right]} \\
{[0]} & {\left[A_{2}\right]-[I]}
\end{array}\right]^{-1}\left\{\begin{array}{l}
\left\{B_{1}\right\} \\
\left\{B_{2}\right\}
\end{array}\right\}
$$

The matrices $\left[A_{1}\right],\left[A_{2}\right],\{B 1\}$ and $\{B 2\}$ incorporate the structural influence coefficients and the coefficients from the expressions of $\left(N_{\text {stat }}\right)_{i}$ and $\left(M_{\text {stat }}\right)_{i}$. The details of this derivation are given in ref 3 . The above matrix equation can be solved for getting the static deformation distribution $\{\overline{\mathrm{h}}\}$ and $\{\bar{\theta}\}$ along the span.

Dynamic part of equation (12) is given by,

$$
\left[\begin{array}{ll}
{\left[C_{h h}\right]} & {\left[C_{h \theta}\right]} \\
{\left[C_{\theta h}\right]} & {\left[C_{\theta \theta}\right]}
\end{array}\right]\left\{\begin{array}{l}
\left\{N_{d y n}\right\} \\
\left\{M_{d y n}\right\}
\end{array}\right\}=\left\{\begin{array}{l}
\{\delta h\} \\
\{\delta \theta\}
\end{array}\right\}
$$

Substituting the expression for $\mathrm{N}_{\mathrm{dyn}}$ and $\mathrm{M}_{\mathrm{dyn}}$ in the above equation, 


$$
\left[\begin{array}{ll}
{\left[C_{h h}\right]} & {\left[C_{h \theta}\right]} \\
{\left[C_{\theta h}\right]} & {\left[C_{\theta \theta}\right]}
\end{array}\right]\left\{\begin{array}{l}
\left\{a_{2}\left(\ddot{h}_{0}+\delta \ddot{h}\right)+a_{3}\left(\dot{h}_{0}+\delta \dot{h}\right)+a_{4}(\delta \ddot{\theta})+a_{5}(\delta \dot{\theta})+a_{6}(\delta \theta)\right\} \\
\left\{b_{2}\left(\ddot{h}_{0}+\delta \ddot{h}\right)+b_{3}\left(\dot{h}_{0}+\delta \dot{h}\right)+b_{4}(\delta \ddot{\theta})+b_{5}(\delta \dot{\theta})+b_{6}(\delta \theta)\right\}
\end{array}\right\}=\left\{\begin{array}{l}
\{\delta h\} \\
\{\delta \theta\}
\end{array}\right\}
$$

The expressions for the aerodynamic coefficients $\left(a_{2} \ldots a_{6}\right.$ and $\left.b_{2} \ldots b_{6}\right)$ are given in the ref [3]. The above equation can be expanded to the equation below,

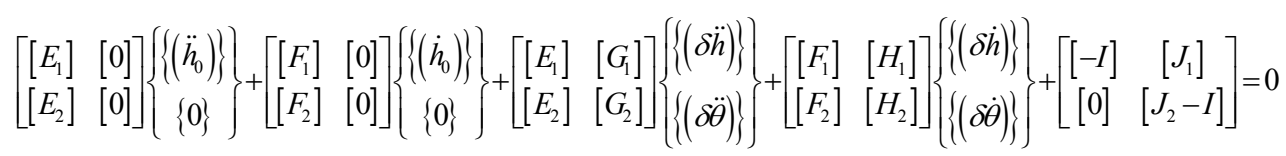

Where the matrices $[E],[F],[G],[H]$ and $[\mathrm{J}]$ incorporate the structural minuence coefficients and the coefficients from the expressions of $\left(N_{d y n}\right)_{i}$ and $\left(M_{d y n}\right)_{i}$. The details of the derivation are given in ref [3].

The imposed motion is harmonic. It is given by,

$$
h_{0}=H_{0} e^{i \omega t}
$$

$\mathrm{H}_{0}$ is a real number

And the dynamic response is,

$$
\begin{aligned}
& \delta h_{i}=H_{i} e^{i \omega t} \\
& \delta \theta_{i}=\Theta_{i} e^{i \omega t}
\end{aligned}
$$

$H_{i}$ and $\Theta_{i}$ complex numbers.

Substituting equations (20), (21) and (22) in equation (19) we get

$$
\left[\omega^{2}\left[\begin{array}{ll}
{\left[E_{1}\right]} & {[0]} \\
{\left[E_{2}\right]} & {[0]}
\end{array}\right]-i \omega\left[\begin{array}{ll}
{\left[F_{1}\right]} & {[0]} \\
{\left[F_{2}\right]} & {[0]}
\end{array}\right]\right]\left\{\left\{\begin{array}{c}
\left.\left(H_{0 i}\right)\right\} \\
\{0\}
\end{array}\right\}=\left[-\omega^{2}\left[\begin{array}{ll}
{\left[E_{1}\right]} & {\left[G_{1}\right]} \\
{\left[E_{2}\right]} & {\left[G_{2}\right]}
\end{array}\right]+i \omega\left[\begin{array}{ll}
{\left[F_{1}\right]} & {\left[H_{1}\right]} \\
{\left[F_{2}\right]} & {\left[H_{2}\right]}
\end{array}\right]+\left[\begin{array}{cc}
{[-I]} & {\left[J_{1}\right]} \\
{[0]} & {\left[J_{2}-I\right]}
\end{array}\right]\right]\right]\left\{\left\{\begin{array}{l}
\left\{\left(H_{i}\right)\right\} \\
\left\{\left(\Theta_{i}\right)\right.
\end{array}\right\}\right\}
$$

Moreover, $\left\{H_{i}\right\}$ and $\left\{\theta_{i}\right\}$ can be found out from the above equation..

\section{Aerodynamic Performance}

The static and the dynamic deformations obtained through the above aeroelastic model are used to calculate the aerodynamic performance of the wing [1].

\section{Normal force calculation}

The wing's aspect ratio is assumed large enough that there is no flow in the spanwise direction. That means the flow over each section is essentially chordwise. Further, the wing is designed in such a way that none of the panels stalls during the entire flap cycle. The sections normal force due to circulation is given by

$$
\left(\mathrm{N}_{\mathrm{c}}\right)_{\mathrm{i}}=\frac{\rho \mathrm{U}^{2}}{2} \mathrm{C}_{\mathrm{n}}(\mathrm{y}) \mathrm{c}_{\mathrm{i}} \Delta \mathrm{y}_{\mathrm{i}}
$$

The normal force due to apparent mass acting at the midchord and is given by 


$$
\left(N_{a}\right)_{i}=\frac{\rho \pi c_{i}^{2}}{4} \dot{v}_{2} \Delta y_{i}
$$

Therefore, the section's total aerodynamic normal force is given by:

$$
\left(\mathrm{N}_{\text {aero }}\right)_{\mathrm{i}}=\left(\mathrm{N}_{\mathrm{c}}\right)_{\mathrm{i}}+\left(\mathrm{N}_{\mathrm{a}}\right)_{\mathrm{i}}
$$

The above equations are explained in ref [3].

\section{Chordwise force calculation}

The forces acting in the chordwise direction are mainly due to camber, leadingedge suction and viscosity. Chordwise forces are different depending on whether the flow is attached or separated.

The chordwise force due to camber is given by

$$
\left(D_{\text {camber }}\right)_{i}=-2 \pi \alpha_{0}\left(\alpha^{\prime}+\bar{\theta}\right) \frac{\rho U V}{2} c_{i} \Delta y_{i}
$$

The expression for the chordwise force due to leading-edge suction is given by

$$
\left(\mathrm{T}_{\mathrm{s}}\right)_{\mathrm{i}}=\eta_{\mathrm{s}} 2 \pi\left(\alpha^{\prime}+\bar{\theta}-\frac{1}{4} \frac{\mathrm{c} \dot{\theta}}{\mathrm{U}}\right)^{2} \frac{\rho \mathrm{UV}}{2} \mathrm{c}_{\mathrm{i}} \Delta \mathrm{y}_{\mathrm{i}}
$$

where $\eta_{s}$ is the efficiency factor.

There is a chordwise friction drag due to viscosity. It is given by

$$
\left(D_{f}\right)_{i}=\left(C_{d}\right)_{f} \frac{\rho V_{x}^{2}}{2} c_{i} \Delta y_{i}
$$

The total force in the chordwise direction is given by

$$
\left(F_{x}\right)_{i}=\left(T_{s}\right)_{i}-\left(D_{\text {camber }}\right)_{i}-\left(D_{f}\right)_{i}
$$

The above equations are explained in ref [3].

\section{Calculation of lift and thrust}

By taking the components of the normal and chordwise force in the direction perpendicular and parallel to the flow we can get the instantaneous lift and thrust values. Therefore, they are given by the following expressions

$$
\begin{aligned}
& \mathrm{L}=\mathrm{N} \operatorname{Cos} \theta+\mathrm{F}_{\mathrm{X}} \operatorname{Sin} \theta \\
& \mathrm{T}=\mathrm{F}_{\mathrm{X}} \operatorname{Cos} \theta-\mathrm{N} \operatorname{Sin} \theta
\end{aligned}
$$

These values are for one section. To get the instantaneous lift and thrust values for the entire wing, integration along the span has to be done. Further, these instantaneous lift and thrust values are averaged for the whole flapping cycle.

\section{Results and Discussion}

The model described above was coded in Matlab. The results obtained are shown in figures 4 and 5 . These results are obtained for a particular flexibility distribution. The planform of the wing is given in figure 1. The airfoil chosen is S1020. Other details of the wing such as the flexibility distribution and the airfoil characteristics are given in ref [3]. 


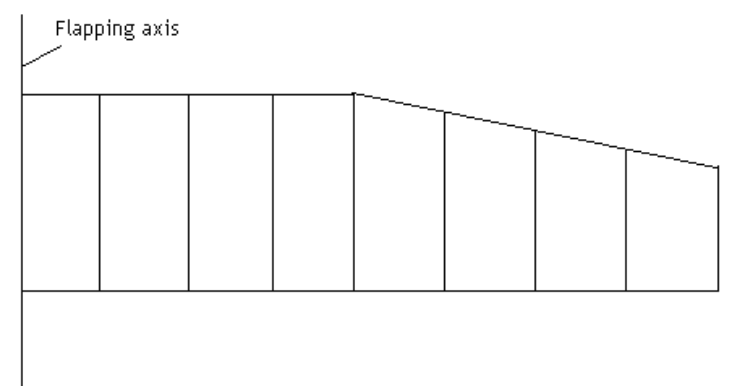

Fig. 1 The plan view of entomopter wing divided into equal strips

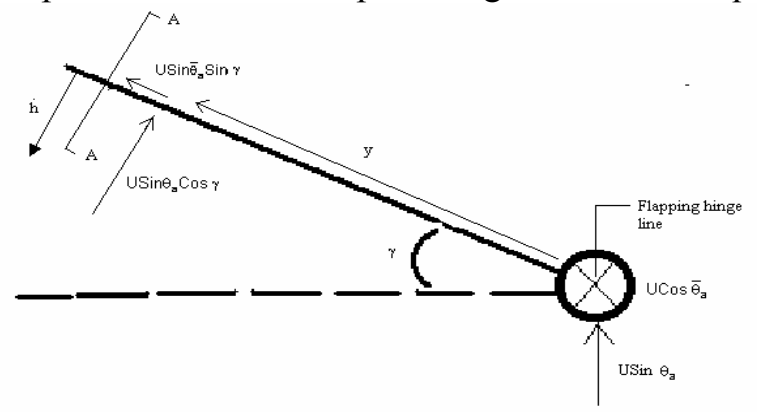

Fig. 2 The front view of the flapping wing at AA

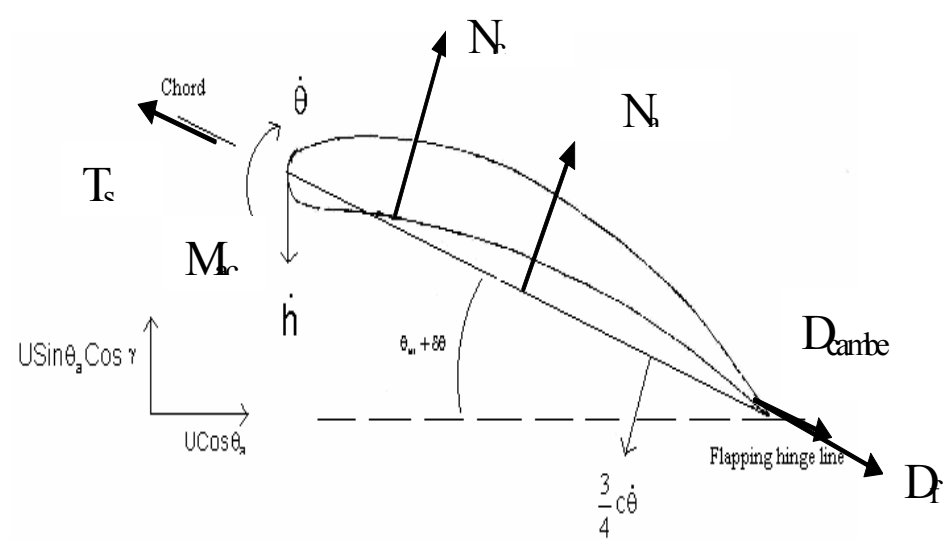

Fig. 3 A schematic figure showing wing section at AA

From figure 4, it is clear that the major portion of the lift comes from the circulatory lift. That is the reason why there is no appreciable change in the average lift due to the increase in flapping frequency. However, there is still a gradual increase. After $3.8 \mathrm{~Hz}$ the lift begins to fall slightly because many of the panels starts stalling. The average thrust value linearly increases as shown in figure 5 . These results are validated with the results given in the paper. 
Average Lift vs Flapping Frequency

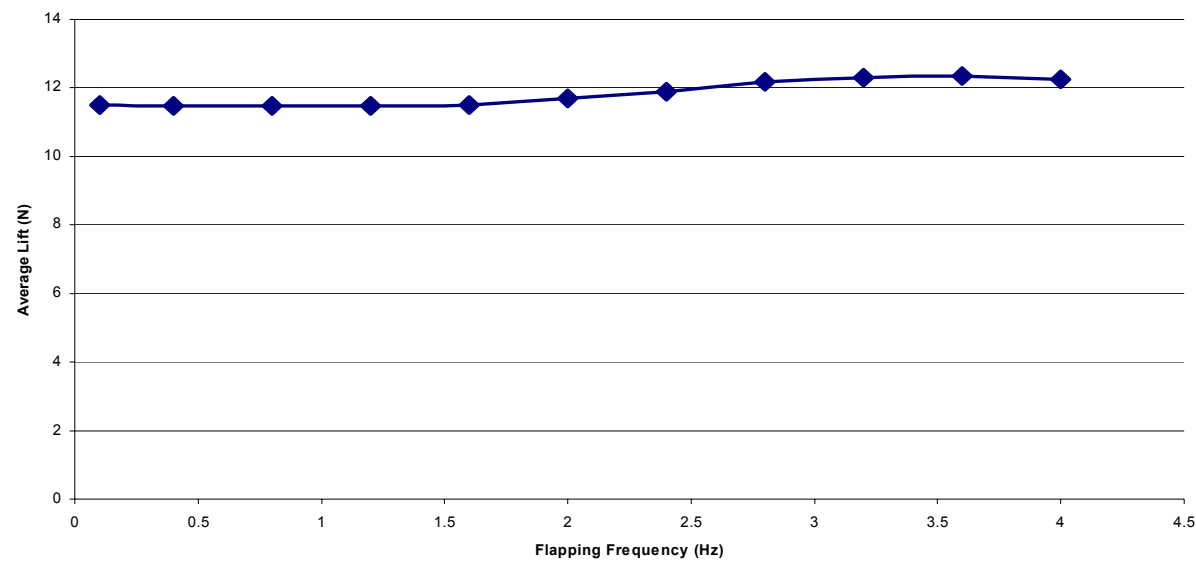

Fig. 4 The graph of Average lift Vs Frequency

Average Thrust vs Flapping frequency

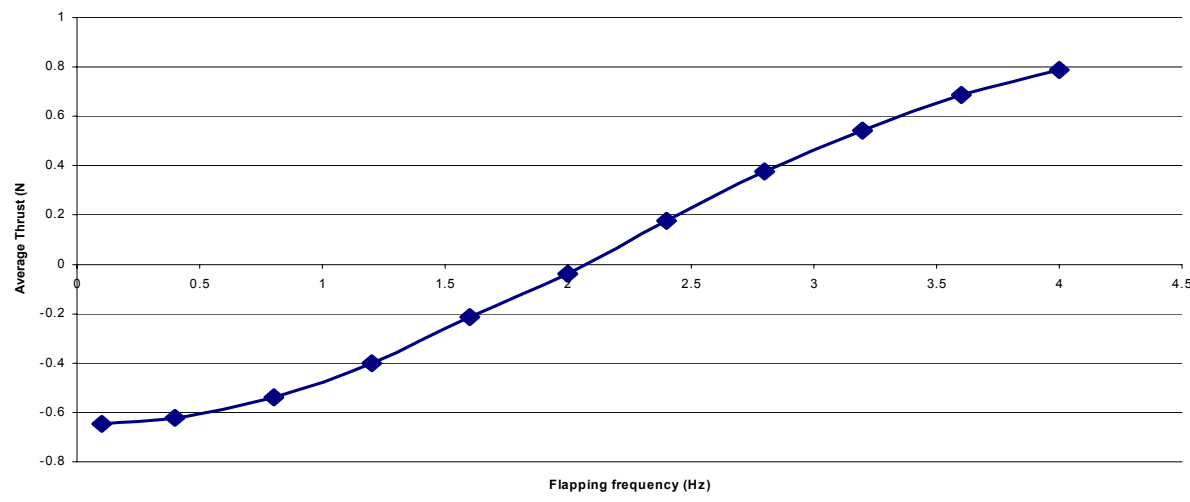

Fig. 5 The graph of Average thrust Vs Frequency

\section{Acknowledgments}

This work was funded by Ministry of Sciences and Higher Education of Republic of Poland as a Grant No. 4 T12C 02330. 


\section{References}

[1] DeLaurier, J.D. An Aerodynamic Model for Flapping-Wing Flight, Aeronautical Journal, Vol. 97, April 1993, pages 125-130.

[2] DeLaurier, J.D. The Development of an Efficient Ornithopter Wing, Aeronautical Journal, Vol. 97, May 1993, pages 153-162.

[3] http://www.casde.iitb.ac.in/IMSL/flapping-wing/formulation.htm

[4] Ramji Kamakoti, Mats Berg, Daniel Ljungqvist and Wei Shyy. A Computational Study of Biological Flapping Wing Flight, Transactions of the Aeronautical Society of the Republic of China, Vol 32, No 4, pages 266-279 (2000).

[5] Raymond L. Bisplinghoff, Holt Ashley and Robert L. Halfman. Aeroelasticity. Addison-Wesley Publishing Company, Inc, Massachusetts, USA, 1955.

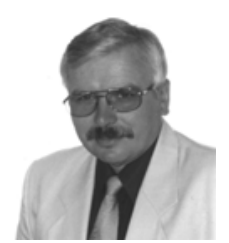

Prof. Krzysztof S. Sibilski PhD Eng., born in 1952 in Białystok. He received the full professor title in 2006. From 1980 to 1999 he was assistant, adjunct, and assistant professor at the Military University of Technology in Warsaw. Science 2000 he has been associate professor (from 2005 full professor) at the Air Force Institute of Technology. He is author of 5 books and above 170 technical papers on aircraft and helicopter flight dynamics, Micro Aerial Vehicles flight dynamics and control, performance of aircraft and helicopters, and aircraft accident reconstruction and simulation. Prof. Sibilski is associate fellow of the AIAA, member of the Society of Applied and Industrial Mathematic, associate member of the Royal Aeronautical Society in London, and member of the Polish Society of Theoretical and Applied Mechanics.

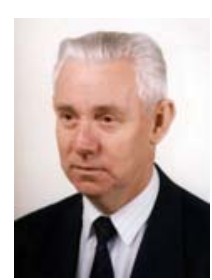

Prof. Jerzy Lewitowicz, PhD Eng., born in 1933 in Hrubieszów, holds the position of the tenured professor at the Instytut Techniczny Wojsk Lotniczych (Air Force Institute of Technology). The main lines of work comprise: advances in the most recent military technologies, in particular aeronautical ones; the aircraft engineering as well as the operationaluse/maintenance of airplanes and helicopters, with special attention paid to the diagnostics. A member of the international aeronautical organizations: AIAA, ICAS. His scientific output comprises more than 250 publications. A co-author of eight books and 27 inventions. He holds the rank of Brigadier General (Ret).

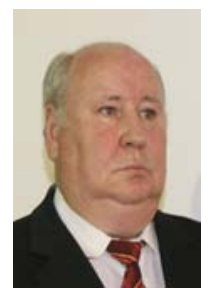

Grzegorz Kowalczyk PhD Eng. Scentific Consultant at Air Force Institute of Technology in Warsaw. Specialisation: mechanical engineering and machine operation/maintenance, transport, systems safety and reliability. 